\title{
Development and Validation of a Digital Literacy Scale for Teenagers
}

\author{
Isabel Rodríguez-de-Dios \\ University of Salamanca \\ Faculty of Social Sciences \\ Observatorio de los Contenidos \\ Audiovisuales \\ 37007 Salamanca (Spain) \\ (+34) 655078900 \\ isabelrd@usal.es
}

\author{
Juan-José Igartua \\ University of Salamanca \\ Faculty of Social Sciences \\ Observatorio de los Contenidos \\ Audiovisuales \\ 37007 Salamanca (Spain) \\ (+34) 923294500 (ext. 3111) \\ jigartua@usal.es
}

\author{
Alejandro González-Vázquez \\ University of Salamanca \\ Faculty of Social Sciences \\ Observatorio de los Contenidos \\ Audiovisuales \\ 37007 Salamanca (Spain) \\ (+34) 609790756 \\ alejandro.gonzalezvazq@gmail.com
}

\begin{abstract}
Research related to digital literacy has grown exponentially in recent years. Its importance is that some scholars suggest that digital skills are a prevention tool against the risks of digital technologies. These risks are especially important because of their psychological consequences on adolescents. Thus, digital literacy could be a health prevention tool. The purpose of this research was to develop and validate a scale to assess digital literacy on teenagers. A self-report questionnaire with 47 items measured in a 5-point Likert scale was developed. After a pilot study, the questionnaire was administered to a sample composed by 715 secondary school students from 13 schools in Spain, aged between 12 and 20 years. Exploratory factor analysis revealed the existence of six factors: technological skill, personal security skill, critical skill, devices security skill, informational skill and communication skill. The scale demonstrated support for internal consistency reliability in most of the factors, with Cronbach's Alpha levels ranging from .63 to .75, and validity. Further research is needed to confirm the factor structure.
\end{abstract}

\section{Categories and Subject Descriptors}

- Social and professional topics Student assessment • Social and professional topics Information technology education - General and reference Surveys and overviews • General and reference $\sim$ Measurement • Applied computing Psychology

\section{General Terms}

Measurement, Reliability.

\section{Keywords}

Digital literacy, digital skills, scale development, adolescents, assessment.

\section{INTRODUCTION}

It is obvious that digital technology has an impact on society. Over the last few years, the way we work, socialize, communicate, entertain ourselves, relax and live has changed due to technological advancements. In this regard, one aspect that has also changed is the concept of literacy. Traditionally, the term literacy has referred to the ability to read and write. However, with the passage of time, other types of literacies have emerged, such as information literacy, media literacy and digital literacy (also known as ICT literacy or technological literacy). In the case of digital literacy, the fundamental role of technology has increased its importance. Nowadays, it is essential to know how to use properly digital devices such as computers or mobiles phones. For this reason, the concepts of digital literacy and digital skills have increasingly been debated.

\subsection{Concept of Digital Literacy}

The concept of digital literacy has changed over the years and nowadays the terminology is still very confused [4;24] as there is no agreement between scholars. In the beginning, this term was based specifically on an instrumental knowledge of hardware and software. Consequently, a person was digital literate if they knew how to use, for example, a word processor in the computer. Then, throughout the 1990s, some authors used this term to refer to an ability to read and understand hypertextual and multimedia texts [3]. However, over time, the concept begins to be seen as something different than a mere ability to use a software or a device. Accordingly, it involves both expertise and skills in the mechanical use as well as knowledge and skills about using these devices for different purposes [8]. Moreover, some authors stress the idea that we cannot adequately understood these digital media if we persist in regarding them simply as a matter of machines, techniques, and software, due to the fact that the internet, computer games, mobile phones and other contemporary technologies provide new ways of mediating and representing the world and of communicating [5]. Thus, the importance of technology is not the technology itself, but the intellectual, social, and ethical use we make of it [1], and a concept of digital literacy should take into account this too.

Therefore, we could define digital literacy as the awareness, attitude and ability of individuals to appropriately use digital tools and facilities to identify, access, manage, integrate, evaluate, analyze and synthesize digital resources, construct new knowledge, create media expressions, and communicate with others, in the context of specific life situations, in order to enable constructive social action; and to reflect upon this process [23; 24]. Furthermore, it consists in using a new medium so that it provides advantages over other forms of learning and, at the same time, be critical and aware of the impact of that environment on oneself [40]. 
It is important to stress that the concept of digital literacy has been developed after the others literacies. For this reason, it draws on them and include aspects related to information literacy or media literacy [23]. As a result, we could say that digital literacy is composed of other literacies [4; 17]. For example, the ability to identify and analyze information in a digital environment would be related to information literacy.

Taking the literature into account, and considering adolescents as our target population, we rely on a model of digital literacy with five dimensions [36]:

- Technological or Instrumental Skill: Ability to effectively use digital technologies.

- Communication Skill: Ability to communicate through digital technologies.

- Information Skill: In short, information skill refers to the ability to find information, obtain it, and evaluate its relevance in the digital environment.

- Critical Skill: Ability to critically analyze the information obtained.

- $\quad$ Security Skill: Ability to use interactive communication without risks and dangers.

In this sense, we should emphasize that, despite the fact that new generations are digital natives and they are at the forefront of new technologies, they have difficulty in managing information, assessing the credibility of information, building their digital identity, and managing their privacy online [14]. Therefore, we presuppose that, in spite of being digital natives, they are not digital literates, as the frequent use of digital devices does not imply digital literacy. Consequently, it is the same with media literacy: the mass consumption and indiscriminate use of media is not associated with knowledge of the codes of visual language. That is the reason why users are still defenceless against media messages [26].

\subsection{Importance of Digital Literacy}

In recent years, research related to digital literacy has grown exponentially. One reason for this is, nowadays, digital skills are becoming essential in a range of disciplines and professional occupations and in different aspects of people's lives. Thus, being technologically savvy or competent has become the 'must have' skill in our society [7]. In the case of adolescents, another reason is some scholars suggest that we must train minors in digital skills and make them digital literates, as a prevention tool against the risks of digital technologies [8; 11; 20; 28; 35; 39]. Thus, through this training, they could become digitally literate and more competent and confident in the digital environment [36].

In this regard, when experts talk about risks of digital technologies they usually refer to cyberbullying, sexual harassment or grooming, exposure to pornography and violence, sexting, contact with strangers and impersonation [21; 42; 29]. The major problems arising from these risks are their psychological consequences that could affect their health and their quality of life. Thus, many studies have shown the existence of a link between suffering cyberbullying and suffering anxiety, depression, stress, sleep disturbance, feelings of anger and frustration, irritability, suicidal ideation, suicide attempts and even suicides [9; $16 ; 27 ; 37]$. A similar type of effects have sexting and harassment, which have been linked to emotional distress, anxiety, depression and eating disorders, such as anorexia [10; 13;
47]. And with reference to exposure to sexually explicit online material, it is related to recreational attitudes toward sex, notions of women as sex objects, body dissatisfaction, stimulation of sexual preoccupancy and reduction of sexual satisfaction [30; 31; 32; 33; 34].

\subsection{Digital Literacy Measures}

Over the last few years, because of the growing importance of digital skills, several digital literacy measures have been proposed. However, the challenge for this assessment is principally the dare of adapting to the frequent and deep changes in technology [6; 46]. Thus, the first measuring instruments were focused on computers, but today they are obsolete. For this reason, some new measures have been developed to replace them, as use of the Internet requires more skills than the use of a computer [42; 44].

Kuhlemeier and Hemker [18] administered a test for measuring Internet skills for school to secondary students aged 13-15. It contained 36 items and four interrelated domains were represented in the instrument: know how to use the Internet to search for relevant information; be able to communicate with others via e-mail; be familiar with current Internet terminology; and have a command of some general windows principles and word processing skills. On the other hand, Lau and Yuen [19] developed a perceived ICT literacy scale, with 17 items, for secondary students. An exploratory factor analysis and a secondorder confirmatory analysis revealed that the scale, which was internally consistent, consists of three subscales (information literacy, internet literacy and computer literacy). However, both tests did not contain items or factors regarding the security of the use of digital devices.

Likewise, van Deursen, Helsper and Eynon [44] developed an Internet Skills Scale. Their online survey was completed by a random sample of 630 Internet users from the UK and the Netherlands. The exploratory factor analysis revealed six factors: operational, navigational, mobile, informational, social, and creative. Furthermore, in the project EU Kids Online [39], children's digital skills were assessed by asking 25,000 European 11-16-year-old internet users. A factor analysis showed that the eight skills included in the survey were all correlated with each other, forming a single scale.

In any case, although many studies have defined and conceptualized this type of literacy, there is a lack of research on developing measures of literacy [19]. Moreover, the problem with most of these instruments is that they only take into account the Internet $[18 ; 41 ; 44]$, not the rest of the digital environment. However, digital society is much more than the Internet. Therefore, limiting it only to the Internet ignores an important part of human actions in electronic space [38]. Moreover, some of the measures refer to the general public or adults. Nonetheless, our target population is minors. For this reason, the goal of the present study was to develop and validate a scale to assess students' digital literacy and the different digital skills.

\section{METHOD}

In order to fulfil this objective, we designed a self-report questionnaire, which is the most frequently used method for measuring digital skills [18]. Although observational studies have been proven to be very suitable to provide a realistic view of people's digital skills, their cost and time are a strong limitation [45]. However, with self-report questionnaires, one can present 
the students with a large number of questions on a wide range of digital skills in a short time. Scoring is simple, fast and cheap [18]. In any case, it is important to note that there is no agreement on the use of self-report measures. Thus, there is research evidence that self-ratings tend to be overly positive as compared to objective test results [18]. Nevertheless, other studies have shown a relation between perceived skill and actual skill [7; 15], suggesting that self-reported measures may be used as a proxy for actual skill measures.

To develop the scale of digital skills, we have built on previous researches that have developed lists of dimensions and indicators to measure digital skills $[2 ; 12 ; 19 ; 22 ; 25 ; 39 ; 43 ; 45]$. We generated a list of 47 items that were measured in a 5-point Likert scale (1: strongly disagree to 5: strongly agree) for the five dimensions of digital literacy.

After scanning the literature and generating items, the questionnaire was developed and administered to teenagers at secondary schools on two phases. First, we conducted a pilot study, in order to improve the scale, in which 208 students 12-17 years of age completed the pencil and paper questionnaire $(52.7 \%$ girls). After a psychometric analysis, we excluded 11 items that had extreme values of skewness and kurtosis, identified words that were difficult to understand for respondents, and excluded another item because the students were not able to understand it ("I am able to recognize if the information is ideologically biased”).

Secondly, from March to May 2016, we conducted a survey among 715 adolescents from thirteen schools of secondary education (state and private) in both rural and urban areas of Spain (52\% girls). The age of respondents varied between 12 and 18 years with a mean age of 13.97 (SD 1.31). Participants were administered a paper-and-pencil questionnaire under the supervision of a researcher and teacher during class.

\section{RESULTS}

The skills items in the survey were examined using an exploratory factor analysis. Prior to this step, we performed the Bartlett's test of sphericity to investigate the factorability of the data and the Kaiser-Meyer-Olkin (KMO) test to measure the sampling adequacy [19]. The KMO measure of sampling adequacy yielded a value of .90 and the test of sphericity was significant $\left(\chi^{2}(595)=\right.$ $5862,715, \mathrm{p}<, 001)$, meaning that the data were suitable for structure detection.

Because of these values, we performed an exploratory factor analysis using the principal component extraction method and varimax rotation on the 35 items with the aim of identifying the factors. One item with a low communality $(<.30)$, a factor with only one item loading on it, and another factor with no theoretical association between its four items and a low eigenvalue, were removed. Finally, the EFA revealed the existence of six factors with eigenvalues over 1.0 that accounted for $44.3 \%$ of the total variance: technological skill, personal security skill, critical skill, devices security skill, informational skill and communication skill. Thus, the factor that was originally set as security skill is divided into two security categories: personal security skill and devices security skill. The internal consistency reliability of the factors was also examined using Cronbach's alpha and it was found to be reliable in five of the six factors, with Cronbach's Alpha levels ranging from .63 to .75 . However, the communication skill factor showed an unacceptable Cronbach's alpha value $(\alpha=.46)$. As we are in the early stages of research, even when we acknowledge that the reliability of this factor is low, we decided to retain the factor with the aim of improving it in future research.

In any case, and in respect of the development of the digital literacy scale, the result shows that the assessment tool resembles the model originally proposed [36]. It is composed of six components and 29 items:

- Technological or Instrumental Skill: Ability to effectively use digital technologies.

- Communication Skill: Ability to communicate through digital technologies.

- Information Skill: In short, information skill refers to the ability to find information, obtain it, and evaluate its relevance in the digital environment.

- Critical Skill: Ability to critically analyze the information obtained.

- Personal security Skill: Ability to use interactive communication without taking risks and dangers that could affect the personal safety of minors.

- Devices security Skill: Take precautions to keep digital devices safe and avoid potential threats, such as viruses and spyware.

Table 1 reports the six factor solution with the corresponding eigenvalues, the explained variance and the Cronbach's value for each factor. It also reports the factor loadings for each item on each factor.

\section{CONCLUSIONS}

The purpose of this research was to create a methodological tool to assess the level on digital literacy of teenagers. Therefore, we developed and validated a scale with six different digital skills: technological skill, personal security skill, critical skill, devices security skill, informational skill and communication skill. The analyses indicate that the instrument is valid in terms of construct and reliability, except in one of the factors.

As we said before, digital literacy has become an important issue nowadays, especially for minors. Given the fact that they have increased the use of interactive technologies and they spend more and more time with them, they should be prepared to use these devices without risks. Taking into account that some researchers have suggested that we must make minors digital literates as a prevention tool against the risks of digital technologies $[8 ; 11 ; 20$; 28; 35; 39], the instrument developed in this paper will allow scholars to explore the potential of digital skills as a prevention tool against digital risks, such as cyberbullying, sexual harassment or impersonation. Moreover, as these tools has been developed for measuring digital literacy on teenagers, it could have usefulness in testing the relationship between this construct and others, like gender or age. 
Factors (items of the scale: know how to...)

Technological skill

Bookmark a website I like so I can view it later

Download/save a photo I found online

Download information I found online

Connect always to a Wi-Fi network from smartphone, no matter the device or where I am

Use shortcut keys (e.g. CTRL+C o cmd+C for copy)

I don't like downloading apps for smartphones as I find difficult to learn how to use them (recoded)

If I want to install new programs on my computer, I will ask someone to do it for me because I don't know (recoded)

\begin{tabular}{|c|c|c|c|c|}
\hline Personal security skill & & 2.311 & $6.60 \%$ & .73 \\
\hline \multicolumn{5}{|l|}{ Deactivate the function showing my geographical position (e.g. Facebook, apps) } \\
\hline \multicolumn{5}{|l|}{ I know when I can post pictures and videos of other people online } \\
\hline \multicolumn{5}{|l|}{ Use 'report abuse' buttons on social media sites (e.g. Someone uses my photo without my permission) .637 } \\
\hline $\begin{array}{l}\text { Change the sharing settings of social media to choose what others can see about me (friends } \\
\text { of friends, friends only, only me) }\end{array}$ & .585 & & & \\
\hline I know the consequences of illegal downloading of music and mo & .425 & & & \\
\hline Critical skill & & 1.898 & $5.42 \%$ & .75 \\
\hline Compare different sources to decide if information is true & .707 & & & \\
\hline Determine if the information I find online is reliable & .675 & & & \\
\hline Identify the author of the information and evaluate their reliability & .646 & & & \\
\hline Compare different apps in order to choose which one is most reliable and secure & .589 & & & \\
\hline If I meet someone online, I know how to check if their profile is real & .381 & & & \\
\hline Devices security skill & & 1.454 & $4.15 \%$ & .72 \\
\hline Use software to detect and remove viruses & .751 & & & \\
\hline Detect a virus in my digital device & .746 & & & \\
\hline Block unwanted or junk mail/spam & .574 & & & \\
\hline $\begin{array}{l}\text { If something doesn't work occurs while I am using a device (computer, smartphone, etc.), I } \\
\text { usually know what it is and how to fix the problem }\end{array}$ & .500 & & & \\
\hline Informational skill & & 1.386 & $3.96 \%$ & .63 \\
\hline I find hard to decide what the best keywords are for online searching (recoded) & 697 & & & \\
\hline I find confusing the way in which many websites are designed (recoded) & 641 & & & \\
\hline Sometimes I find difficult to determine how useful the information is for my purpose (recoded) & .596 & & & \\
\hline I get tired when looking for information online & .570 & & & \\
\hline Sometimes I end up on websites without knowing how I got there & .500 & & & \\
\hline Communication skill & & 1.060 & $3.02 \%$ & .46 \\
\hline $\begin{array}{l}\text { Depending on who I want to communicate with, it is better to use one method over the other } \\
\text { (make a call, send a WhatsApp message, send an email, etc.) }\end{array}$ & .723 & & & \\
\hline Send any file to a contact using a smartphone & .463 & & & \\
\hline No matter with who I communicate: emojis are always useful & .308 & & & \\
\hline
\end{tabular}

Factor Eigenvalue Explained loadings Eigenvalue variance

$7.406 \quad 21.16 \% \quad .73$

.731

.684

.498

.498

.454

.445

.440 


\subsection{Limitations and further research}

Our research has some limitations that should be addressed in the future. First of all, the reliability of the communication skill factor should be improved with the aim of ensuring internal consistency. Moreover, and with reference to the sample, although we utilized a large and diverse sample of students, we only went to those schools in which principals and teachers allowed us to conduct the study. Therefore, we had to use a convenience sample instead of a random sample.

Additionally, further research using a different sample and conducting a confirmatory factor analysis is needed to establish the structural validity of the scale. Moreover, we could use this instrument to examine the relationship between digital literacy and online risks behaviors. It would also be interesting to analyze whether there are explanatory variables, mediating variables and moderating variables in the relationship. Therefore, examination of the role of variables such as adolescent's ICT attitude or parental mediation in this relationship should be considered in future research.

\section{ACKNOWLEDGMENTS}

This work is funded by the Government of Castile and León and the European Social Fund (EDU/1083/2013). Our sincere thanks to the students, teachers and principals in the fourteen schools and high schools of secondary education for contributing data for analysis.

\section{REFERENCES}

[1] Area, M., Gros, B., and Marzal, M. A. 2008. Alfabetizaciones y tecnologías de la información y la comunicación. Síntesis, Madrid.

[2] Arnone, M., Small, R., and Reynolds, R. 2010. Supporting Inquiry by Identifying Gaps in Student Confidence: Development of a Measure of Perceived Competence. School Libraries Worldwide, 16, 1, 47-60.

[3] Bawden, D. 2001. Information and digital literacies: a review of concepts. $J$ Doc, 57, 2, 218-259. DOI= http://doi.org/10.1108/EUM0000000007083

[4] Bawden, D. 2008. Origins and concepts of digital literacy. In C. Lankshear and M. Knobel (Eds.). Digital literacies: Concepts, policies and practices, 17-32. Peter Lang Publishing, New York.

[5] Buckingham, D. 2008. What do young people need to know about digital media? In C. Lankshear and M. Knobel (Eds.). Digital Literacies: Concepts, Policies and Practices, 73-88. Peter Lang Publishing, New York.

[6] Bunz, U. 2004. The Computer-Email-Web (CEW) Fluency Scale-Development and Validation. Int J Hum-Comput Int, 17, 479-506. DOI= http://doi.org/10.1207/s15327590ijhc1704_3

[7] Bunz, U., Curry, C., and Voon, W. 2007. Perceived versus actual computer-email-web fluency. Comput Hum Behav, 23, 5, 2321-2344. DOI= http://doi.org/10.1016/j.chb.2006.03.008

[8] Chisholm, J. F. 2006. Cyberspace violence against girls and adolescent females. Annals of the New York Academy of Sciences, 1087, 74-89. DOI= http://doi.org/10.1196/annals.1385.022
[9] Dehue, F., Bolman, C., and Völlink, T. 2008. Cyberbullying: youngsters' experiences and parental perception. Cyberpsychology \& Behavior, 11, 2, 217-223. DOI= http://doi.org/10.1089/cpb.2007.0008

[10] Drouin, M., Ross, J., and Tobin, E. 2015. Sexting: A new, digital vehicle for intimate partner aggression? Comput Hum Behav, 50, 197-204. DOI= http://doi.org/10.1016/j.chb.2015.04.001

[11] Eshet-Alkalai, Y. 2004. Digital Literacy: A Conceptual Framework for Survival Skills in the Digital era. Journal of Educational Multimedia and Hypermedia, 13, 1, 93-106.

[12] Ferrari, A. 2012. Digital Competence in Practice: An Analysis of Frameworks. Joint Research Centre, Luxembourg.

[13] Gati, A., Tényi, T., Túry, F., and Wildmann, M. 2002. Anorexia nervosa following sexual harassment on the internet: A case report. Int J Eat Disorder, 31, 4, 474-477. DOI= http://doi.org/10.1002/eat.10029

[14] González, N. 2012. Alfabetización para una cultura social, digital, mediática y en red. Revista Española de Documentación Científica, 0, 17-45. DOI= http://doi.org/10.3989/redc.2012.mono.976

[15] Hargittai, E. 2005. Survey Measures of Web-Oriented Digital Literacy. Soc Sci Comput Rev, 23, 3, 371-379. DOI= http://doi.org/10.1177/0894439305275911

[16] Hinduja, S., and Patchin, J. W. 2010. Bullying, cyberbullying, and suicide. Archives of Suicide Research : Official Journal of the International Academy for Suicide Research, 14(3), 206-221. DOI= http://doi.org/10.1080/13811118.2010.494133

[17] Koltay, T. 2011. The media and the literacies: media literacy, information literacy, digital literacy. Media Cult Soc, 33, 2, 211-221. DOI= http://doi.org/10.1177/0163443710393382

[18] Kuhlemeier, H., and Hemker, B. 2007. The impact of computer use at home on students' Internet skills. Comput Educ, 49, 2, 460-480. DOI= http://doi.org/10.1016/j.compedu.2005.10.004

[19] Lau, W. W. F., and Yuen, A. H. K. 2014. Developing and validating of a perceived ICT literacy scale for junior secondary school students: Pedagogical and educational contributions. Comput Educ, 78, 1-9. DOI= http://doi.org/10.1016/j.compedu.2014.04.016

[20] Lee, S.-J., and Young Gil Chae. 2012. Balancing Participation and Risks in Children's Internet Use: The Role of Internet Literacy and Parental Mediation. Cyberpsychology, Behavior, and Social Networking, 15, 5, 257-62.

[21] Livingstone, S., Haddon, L., Görzig, A., and Ólafsson, K. 2011a. Risks and safety on the internet: The perspective of European children. Full findings. EU Kids Online, LSE, London. DOI= http://doi.org/2045-256X

[22] Livingstone, S., Haddon, L., Görzig, A., and Ólafsson, K. 2011b. Technical report and user guide: the 2010 EU kids online survey, 264. EU Kids Online, LSE.

[23] Martin, A. 2005. DigEuLit European framework for digital literacy: a progress report. Journal of eLiteracy, 2, 130-266. 
[24] Martin, A. 2008. Digital Literacy and the "Digital Society." In C. Lankshear \& M. Knobel (Eds.), Digital Literacies: Concepts, Policies \& Practices, 151-176. Peter Lang Publishing, New York. DOI= http://doi.org/10.1093/elt/ccr077

[25] Mascheroni, G., and Ólafsson, K. (2014). Net Children Go Mobile: risks and opportunities (Second Edi). Educatt, Milano.

[26] Moreno, M. D. 2008. Digital literacy: full control of pen drive and mouse. Comunicar, 16, 30, 137-146. DOI= http://doi.org/10.3916/c30-2008-02-007

[27] Nixon, C. L. 2014. Current perspectives: the impact of cyberbullying on adolescent health. Adolescent Health, Medicine and Therapeutics, 5, 143-158. DOI= http://doi.org/10.2147/AHMT.S36456

[28] O’Neill, B., Livingstone, S., and McLaughlin, S. 2011. Final recommendations for policy, methodology and research. EU Kids online, LSE, London.

[29] Ólafsson, K., Livingstone, S., and Haddon, L. 2013. Children's Use of Online Technologies in Europe. A review of the European evidence base. EU Kids Online, LSE, London.

[30] Peter, J., and Valkenburg, P. M. 2006. Adolescents' exposure to sexually explicit online material and recreational attitudes toward sex. $J$ Commun, 56, 4, 639-660. DOI= http://doi.org/10.1111/j.1460-2466.2006.00313.x

[31] Peter, J., and Valkenburg, P. M. 2007. Adolescents' exposure to a sexualized media environment and their notions of women as sex objects. Sex Roles, 56, 5-6, 381395. DOI= http://doi.org/10.1007/s11199-006-9176-y

[32] Peter, J., and Valkenburg, P. M. 2008. Adolescents' Exposure to Sexually Explicit Internet Material and Sexual Preoccupancy: A Three-Wave Panel Study. Media Psychology, 11, 2, 207-234. DOI= http://doi.org/10.1080/15213260801994238

[33] Peter, J., and Valkenburg, P. M. 2009. Adolescents exposure to sexually explicit internet material and sexual satisfaction: A longitudinal study. Hum Commun Res, 35(2), 171-194. http://doi.org/10.1111/j.1468-2958.2009.01343.x

[34] Peter, J., and Valkenburg, P. M. 2014. Does exposure to sexually explicit Internet material increase body dissatisfaction? A longitudinal study. Comput Hum Behav, 36, 297-307. DOI= http://doi.org/10.1016/j.chb.2014.03.071

[35] Rodríguez-de-Dios, I., and Igartua, J. J. 2014. Risks of Interactive Communication: A Digital Literacy Proposal. Proceedings of the Second International Conference on Technological Ecosystems for Enhancing Multiculturality TEEM'14, 653-657. DOI= http://doi.org/10.1145/2669711.2669969
[36] Rodríguez-de-Dios, I., and Igartua, J. J. 2016. Skills of Digital Literacy to Address the Risks of Interactive Communication. JITR, 9, 1, 54-64. DOI= http://doi.org/10.4018/JITR.2016010104

[37] Schneider, S. K., O’donnell, L., Stueve, A., and Coulter, R. W. S. 2012. Cyberbullying, school bullying, and psychological distress: A regional census of high school students. Am J Public Health, 102, 1, 171-177. DOI= http://doi.org/10.2105/AJPH.2011.300308

[38] Sevillano, M. L. 2009. Competencias para el uso de herramientas virtuales en la vida, trabajo y formación permanentes. Pearson, Madrid.

[39] Sonck, N., Livingstone, S., Kuiper, E., and de Haan, J. 2011. Digital Literacy and Safety Skills. EU Kids Online, LSE, London.

[40] Süss, D. 2001. Computers and the Internet in School: Closing the Knowledge Gap. In S. Livingstone and M. Bovill (Eds.). Children and their changing media environment, 221-244. Lawrence Erlbaum Associates, Mahway, NJ.

[41] Torkzadeh, G., and van Dyke, T. P. 2001. Development and validation of an Internet self-efficacy scale. Behav Infor Technol, 20, 4, 275-280. DOI= http://doi.org/10.1080/0144929011005029

[42] Valkenburg, P. M., and Peter, J. (2009). Social Consequences of the Internet for Adolescents. A Decade of Research. Curr Dir Psychol Sci, 18, 1, 1-5. DOI= http://doi.org/10.1111/j.1467-8721.2009.01595.x

[43] van Deursen, A. J. A. M., Helsper, E. J., and Eynon, R. 2014. Measuring digital skills. From Digital Skills to Tangible Outcomes. Project report.

[44] van Deursen, A. J. A. M., Helsper, E. J., and Eynon, R. 2015. Development and validation of the Internet Skills Scale (ISS). Information, Communication \& Society, 1-20. http://doi.org/10.1080/1369118X.2015.1078834

[45] van Deursen, A. J. A. M., van Dijk, J. A. G. M., and Peters, O. (2012). Proposing a Survey Instrument for Measuring Operational, Formal, Information, and Strategic Internet Skills. Int J Hum-Comput Int, 28, 12, 827-837. DOI= http://doi.org/10.1080/10447318.2012.670086

[46] Wilson, M., Scalise, K., and Gochyyev, P. 2015. Rethinking ICT literacy: From computer skills to social network settings. Thinking Skills and Creativity, 18, 65-80. DOI= http://doi.org/10.1016/j.tsc.2015.05.001

[47] Ybarra, M. L., Mitchell, K. J., Wolak, J., and Finkelhor, D. 2006. Examining Characteristics and Associated Distress Related to Internet Harassment: Findings from the Second Youth Internet Safety Survey. Pediatrics, 118, 4, 11691177. DOI= http://doi.org/10.1542/peds.2006-0815 